\title{
Intrathecal Hyperbaric Ropivacaine and Hyperbaric Ropivacaine with Fentanyl in Caesarean Section: A Comparative Study
}

\author{
Dr. Sagar Debbarman ${ }^{1}$, Dr N. Ratan Singh ${ }^{2}$, Prof. S. Sarat Singh ${ }^{3}$, \\ Dr V. Ramesh ${ }^{4}$, Dr Jayalaxmi Bachaspatimayum ${ }^{5}$, Dr Ralte Lalrinmawia ${ }^{6}$. \\ 1, 4, 5, ${ }^{6}$ Post Graduate Trainee, ${ }^{2}$ Associate Professor, ${ }^{3}$ Professor, Department of Anaesthesiology, \\ Regional Institute of Medical Sciences, Imphal, Manipur. \\ Corresponding Author: Dr N Ratan Singh, Department of Anaesthesiology, Regional Institute of Medical \\ Sciences, Imphal, Manipur.
}

\begin{abstract}
:
Background: Ropivacaine is considered to have more selectivity for sensory blockade with lower systemic toxicity compared to agents like bupivacaine. In this study, spinal block characteristics of hyperbaric ropivacaine with and without fentanyl in cesarean section were studied.

Materials and methods: One hundred (100) parturients undergoing elective lower segment cesarean section (LSCS) were recruited in this randomized double-blind controlled study. They were allocated into two groups: Group A $-15 \mathrm{mg} 0.6 \%$ hyperbaric ropivacaine and

Group B - $13.2 \mathrm{mg}$ of $0.6 \%$ hyperbaric ropivacaine $+15 \mu \mathrm{g}$ fentanyl intrathecally. The spinal block characteristics in the two groups were assessed along with the intraoperative hemodynamic changes. The results obtained were statistically analyzed and $p<0.05$ was considered statistically significant.

Results: The sensory onset time in Group A and Group B were $3.23 \pm 0.57$ vs. $1.55 \pm 0.37(p<0.001)$ and the motor onset time to Bromage $1(\mathrm{~min})$ was $3.84 \pm 0.60$ and $2.60 \pm 0.47(p<0.001)$ respectively. The mean peak sensory block level (MPSBL) between group A \& group B were (T4/T6:39/11 vs. 50/0); $p<0.001$. Sensory block

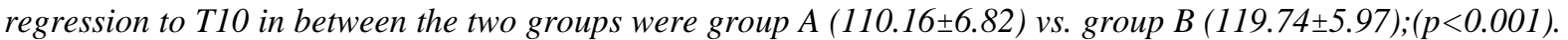
Conclusion: Intrathecal fentanyl as adjuvant to hyperbaric ropivacaine provided faster onset and longer duration of sensory block, early recovery from motor block, better hemodynamic stability without any significant side effects than hyperbaric ropivacaine alone for lower segment caesarean section.
\end{abstract}

Keywords: Ropivacaine, fentanyl, spinal anesthesia, caesarean section

\section{Introduction}

Regional anesthesia has seen resurrection in the past two decades and spinal anesthesia, a form of regional anesthesia, is a common, safe, economical, easy to perform and reliable anesthesia with muscle relaxation for patients undergoing lower abdominal surgery. ${ }^{[1]}$ Moreover, spinal anesthesia is the anesthetic technique of choice and the gold standard for cesarean section. ${ }^{[2]}$

Ropivacaine, a long-acting amide local anaesthetic agent, produces effects via reversible inhibition of sodium ion influx in nerve fibres. Ropivacaine is less lipophilic and is less likely to penetrate large myelinated motor fibres, resulting in a relatively reduced motor blockade, which could be useful when motor blockade is undesirable. The reduced lipophilicity is also associated with decreased potential for central nervous system toxicity and cardiotoxicity. ${ }^{[3]}$

Ropivacaine is available in isobaric form which when used for intrathecal block may cause intraoperative visceral pain, because of variable sensory and motor response. ${ }^{[4]}$ Various neuraxial adjuvants such as opioids, sodium bicarbonate, $\alpha 2$ agonist, $\mathrm{N}$ methyl $\mathrm{D}$ aspartate agonist, etc. are used to improve, hasten or prolong analgesia with local anesthetic agents. ${ }^{[5]}$

Fentanyl, a lipophilic opioid which is 100 times more potent than morphine, has a rapid onset and short duration of action following intrathecal administration. It acts as agonist at $\mu$ opioid receptor to enhance the spinal analgesia when administered epidurally and intrathecally. ${ }^{[6,7]}$

The primary outcome(s) assessed and evaluated in the present study were the onset and regression of motor and sensory blockade, hemodynamic variables, sedation and the side effects (if any) as the secondary outcome after spinal block with hyperbaric ropivacaine with and without fentanyl in cesarean section. Keeping the benefits of ropivacaine in consideration, we hypothesized that lowering the intrathecal dose of ropivacaine with an opioid as an adjunct might benefit by shortening the motor block duration and also by reducing the side effects.

\section{Materials And Methods}

After the Institutional Ethics Committee's approval and written informed consent, 100 parturients of the 
American Society of Anesthesiologists (ASA I and II) ${ }^{[8]}$ 18-45 years, scheduled to undergo elective lower segment cesarean section (LSCS) were recruited in this randomized double-blind controlled study conducted in the department of Anesthesiology of a tertiary care teaching hospital in northeast India.

Based on the data of previous study of Gupta et al. ${ }^{[9]}$, assuming an $\alpha$ value of $0.05, \beta$ value of 0.2 , power $(1-\beta)$ of 80 and using a web based sample size calculator, the sample size was calculated as 46 in each group. Assuming a 5\% dropout rate, the sample size was rounded to 50 parturients in each group.

Using a computer generated randomization; the parturient were allocated into two groups:

- Group A - received $15 \mathrm{mg}$ of $0.6 \%$ hyperbaric ropivacaine intrathecally and

- Group B - received $13.2 \mathrm{mg}$ of $0.6 \%$ hyperbaric ropivacaine $+15 \mu \mathrm{g}$ fentanyl intrathecally

The study drug was prepared by an anesthesiologist not involved in the study. The commercially available ropivacaine was made hyperbaric by adding $0.5 \mathrm{ml}$ of $25 \%$ dextrose to $2 \mathrm{ml}$ of the isobaric ropivacaine. The volume of solution in each group was $2.5 \mathrm{ml}$ with the specific gravity of ropivacaine at 1.01949 at $37^{\circ} \mathrm{C}$ respectively. ${ }^{[10]}$ Parturients with preexisting cardiac or pulmonary diseases, any contraindication to neuro-axial anesthesia, previous spinal surgeries, spinal abnormalities, local site infection, pregnancy induced hypertension, coagulation abnormalities, neurologic or renal dysfunction, on antiarrhythmics or refusal to the technique were excluded from the study.

After preanesthetic evaluation a day before the scheduled day of surgery, baseline non-invasive blood pressure, pulse rate, pulse oximetry (SpO2) were recorded, and after securing an intravenous line with $18 \mathrm{G}$ catheter, the parturients were preloaded with Ringer's Lactate solution @ 10ml/kg, 15 min before initiation of spinal anaesthesia.

Under aseptic and antiseptic conditions, lumbar puncture was performed with 25G Quincke needle (Spinocan, B Braun Medical Melsungen, Germany) at L 3-4 intervertebral space in the left lateral position and after free flow of CSF, the study drug was injected, and patients were placed supine with a wedge under the right hip. All the durations were calculated taking the time of intrathecal injection as time " 0 " (zero).

The sensory blockade was assessed bilaterally in the midclavicular line by loss of pinprick sensation after the intrathecal injection until the surgical anaesthesia was achieved i.e. when $\mathrm{T}_{6}$ dermatome level was achieved. The sensory onset time was taken as the first complaint of numbness and tingling in the lower limb. The motor blockade of lower extremities was evaluated by modified Bromage scale (MBS) ${ }^{[11]}$ :- $0=$ full movement, no power impairment, $1=$ unable to raise extended leg at the hip but able to flex knee, $2=$ unable to flex knee but able to move ankle and $3=$ no motor activity.

The onset time of sensory blockade upto $\mathrm{T}_{6}$ dermatome $(\mathrm{min})$, highest level of sensory blockade, time taken to achieve maximum sensory blockade ( $\mathrm{min})$, total regression of sensory block $\left(\mathrm{T}_{10}\right.$ level), time taken to achieve complete motor block (MBS 3) (min), duration of motor block (MBS 0) (min) were assessed and recorded along with the intraoperative hemodynamic changes.

Heart rate $(\mathrm{HR})$, arterial blood pressure $(\mathrm{BP})$, and oxygen saturation $\left(\mathrm{SpO}_{2}\right)$ were recorded at $0 \mathrm{~min}$, $1 \mathrm{~min}$, $3 \mathrm{~min}$, 10min, $15 \mathrm{~min}$, 20min, 30min and 40min after intrathecal injection of the drug and the incidence of adverse effects viz. nausea, vomiting, shivering, hypotension, respiratory depression, sedation, pruritus and bradycardia were recorded.

The results obtained were tabulated and statistically analyzed using Statistical package for social sciences for windows (SPSS) version 21.0 (Armonk, NY: IBM corp.). Statistical analysis of data was done using Student $t$ test for parametric data and Fisher's Exact Test wherever appropriate. $\mathrm{P}<0.05$ was considered statistically significant.

\section{Results}

The demographic profiles i.e. age, weight and height of the parturients were similar and no statistically significant difference $(\mathrm{p}>0.05)$ was observed between the two groups (Table 1$)$.

Table 1. Demographic profile of the two groups

\begin{tabular}{|l|l|l|l|l|l|}
\hline \multicolumn{1}{|c|}{ Parameters } & \multicolumn{1}{|c|}{$\begin{array}{c}\text { Group A }(\mathbf{n}=50) \\
\text { Mean } \pm \text { SD }\end{array}$} & $\begin{array}{c}\text { Group B }(\mathbf{n = 5 0} \\
\text { Mean } \pm \text { SD }\end{array}$ & t-value & \multicolumn{1}{c|}{ df } & P-value \\
\hline Age (years) & $30.16 \pm 6.12$ & $28.16 \pm 5.59$ & 1.705 & 98 & .091 \\
\hline Weight $(\mathrm{Kg})$ & $57.74 \pm 4.59$ & $57.26 \pm 4.90$ & .505 & 98 & .615 \\
\hline Height(ft.) & $5.26 \pm .142$ & $5.22 \pm .33$ & .699 & 98 & .486 \\
\hline
\end{tabular}

( $p<0.05$, considered significant $)$

The sensory onset time (T6-sec.) in Group A and Group B were 3.23 \pm 0.57 versus $1.55 \pm 0.37$ ( $<<0.001)$ and the motor onset time to Bromage $1(\mathrm{~min})$ was $3.84 \pm 0.60$ and $2.60 \pm 0.47(\mathrm{p}<0.001)$ respectively (Table 2$)$. 
Intrathecal Hyperbaric Ropivacaine and Hyperbaric Ropivacaine with Fentanyl in ....

Table 2. Showing the block characteristics between the two groups

\begin{tabular}{|c|c|c|c|c|}
\hline Parameters & $\begin{array}{c}\text { Group A }(n=50) \\
\text { Mean } \pm \text { SD }\end{array}$ & $\begin{array}{c}\text { Group B }(n=50) \\
\text { Mean } \pm \text { SD }\end{array}$ & $\begin{array}{l}F \text { test/ } \\
\text { ' } t \text { ' test }\end{array}$ & $\mathrm{P}$ value \\
\hline $\begin{array}{l}\text { Sensory onset time T6( } \\
\text { min.) }\end{array}$ & $3.23 \pm 0.57$ & $1.55 \pm 0.37$ & 17.70 & $<0.001$ \\
\hline $\begin{array}{l}\text { Motor onset to modified } \\
\text { Bromage } 1 \\
(\mathrm{~min}) \\
\end{array}$ & $3.84 \pm 0.60$ & $2.60 \pm 0.47$ & 11.38 & $<0.001$ \\
\hline $\begin{array}{l}\text { Time to peak sensory } \\
\text { block level } \\
\text { (TPSBL min.) }\end{array}$ & $4.73 \pm 0.69$ & $3.22 \pm 0.77$ & 10.18 & $<0.001$ \\
\hline $\begin{array}{l}\text { Mean Peak sensory } \\
\text { blocklevel(MPSBL) }\end{array}$ & $\begin{array}{l}\text { T4-39 } \\
\text { T6- } 11\end{array}$ & $\begin{array}{c}\text { T4- } 50 \\
\text { T6- } 0\end{array}$ & $\begin{array}{l}\text { F test } \\
12.26\end{array}$ & $<0.001$ \\
\hline $\begin{array}{l}\text { Time to sensory block } \\
\text { regression to } \mathrm{T} 10 \text { (min.) }\end{array}$ & $110.16 \pm 6.82$ & $119.74 \pm 5.97$ & $\begin{array}{l}\text { 't' test } \\
7.469\end{array}$ & $<0.001$ \\
\hline $\begin{array}{l}\text { MBS onset time (min.) } \\
\text { to B1 }\end{array}$ & $3.84 \pm 0.60$ & $2.60 \pm 0.47$ & 11.38 & $<0.001$ \\
\hline $\begin{array}{l}\text { MBS onset time (min.) } \\
\text { to B3 }\end{array}$ & $6.83 \pm 1.16$ & $4.12 \pm 0.56$ & 14.76 & $<0.001$ \\
\hline $\begin{array}{l}\text { Regression to MBS } \\
\text { B0(min.) }\end{array}$ & $245.02 \pm 22.95$ & $196.22 \pm 16.46$ & 12.21 & $<0.001$ \\
\hline
\end{tabular}

$(\mathrm{p}<0.05$, considered significant $)$

The mean peak sensory block level(MPSBL) between the two groups were group A-T4-39, T6-11 versus group B- T4-50,T6 - $0(\mathrm{p}<0.001)$ respectively. As observed in table 2 , the time to peak sensory block level (TPSBL in min.) was $4.73 \pm 0.69$ versus $3.22 \pm 0.77$ in group A versus group B $(\mathrm{p}<0.001)$. Sensory block regression to $\mathrm{T} 10$ in between the two groups were group A versus group $\mathrm{B}: 110.16 \pm 6.82$ versus $119.74 \pm 5.97$ ( $\mathrm{p}<0.001$; Table 2). Also, the Modified Bromage scale(MBS-B3) onset time (min.) were $6.83 \pm 1.16$ versus $4.12 \pm 0.56$ between group A and Group B and the regression to MBS-B0( min.) were 245.02 \pm 22.95 versus $196.22 \pm 16.46$ respectively (Table 2 ).

There was no incidence of hypotension and bradycardia and all the parturient were haemodynamically stable in both the groups (Fig. 1).

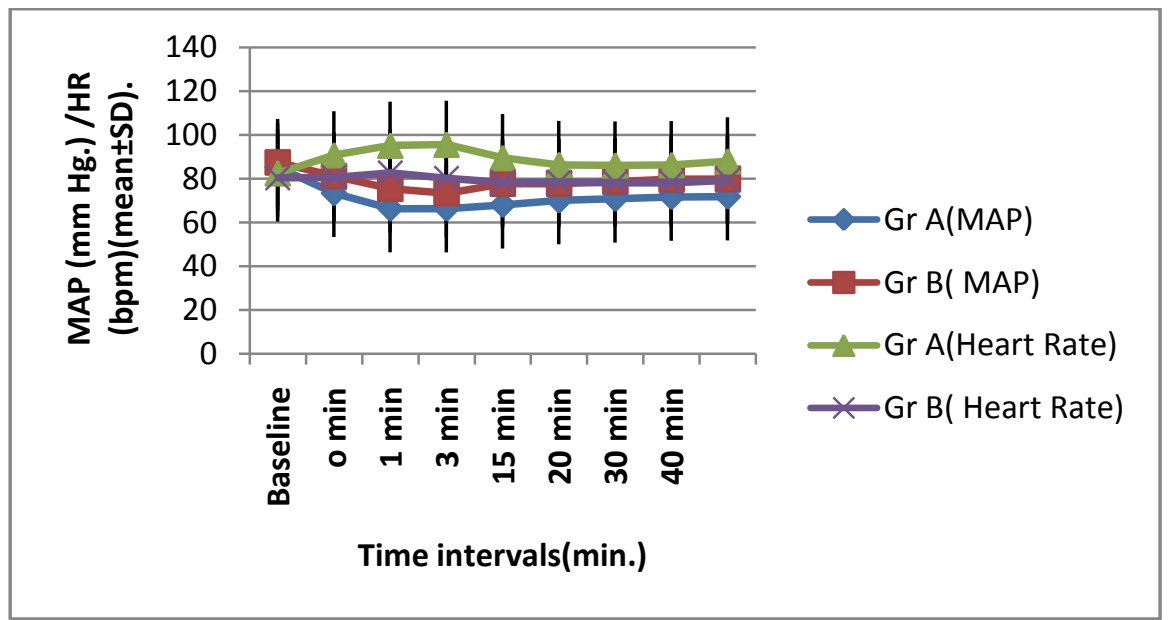

Fig. 1. Showing the changes in MAP and Heart rate at different time intervals

The incidence of nausea was $14(28 \%)$ in the group A and 1(2\%) in group B. In group B, the incidence of sedation was $1(2 \%)$ and pruritus was $3(6 \%)$. Shivering was found in $12(24 \%)$ in the ropivacaine group (Table 3).

Table 3. Showing the side effects in the two groups

\begin{tabular}{|c|c|c|}
\hline Parameters & $\begin{array}{c}\text { Group A } \\
\text { No. ( \%) }\end{array}$ & $\begin{array}{c}\text { Group B } \\
\text { No. ( \%) }\end{array}$ \\
\hline Nausea & $14(28 \%)$ & $1(2 \%)$ \\
\hline Vomiting & 0 & 0 \\
\hline Hypotension & 0 & 0 \\
\hline Bradycardia & 0 & 0 \\
\hline Sedation & 0 & $1(2 \%)$ \\
\hline Pruritus & 0 & $3(6 \%)$ \\
\hline Shivering & $12(24 \%)$ & 0 \\
\hline
\end{tabular}


The neonatal status i.e. birth weight, Apgar score at $1 \mathrm{~min}$. and $5 \mathrm{~min}$. were comparable between the two groups.

\section{Discussion}

Spinal anaesthesia is an accepted technique for lower segment cesarean section and ropivacaine is useful for intrathecal anaesthesia in obstetrics. The parturients in both the groups were matched in this study and comparable in age, body weight, ASA physical status $(\mathrm{p}>0.05)$.

Adequate surgical anaesthesia was achieved in both the groups and there was no case of failed spinal anaesthesia in either group in our study. It is supported by the findings of Gupta $\mathrm{R}$ et al. ${ }^{1}$ who found that intrathecal hyperbaric ropivacaine provided adequate and good quality of sensory and motor block.

In our study, addition of fentanyl to hyperbaric ropivacaine shortened the onset time of sensory and motor block and prolonged the duration of sensory block which is in agreement with Bogra $\mathrm{J}$ et al. ${ }^{[12]}$, where faster onset of sensory block up to T6 occurred in bupivacaine-fentanyl group. However, it differed from observations of Singh $\mathrm{H}$ et al. ${ }^{[7]}$ where the onset time observed was $7.5 \pm 3.2 \mathrm{~min}$ in the fentanyl group. It was also observed that the maximum level of sensory block reached earlier in fentanyl group (3.22 $\pm .77 \mathrm{~min}$. $)$ $(\mathrm{p}<0.001)$ and this is in concurrence with the findings of Yegin et al. ${ }^{[13]}$

In the present study, the mean time (in min) for sensory block regression upto T10 dermatome was 110.16 \pm 6.82 in Group A and $119.74 \pm 5.97$ in Group B (fentanyl group) ( $p<0.001$ ). Singh H et al. ${ }^{[7]}$ conducted a study to evaluate the effect of intrathecal fentanyl on the onset and duration of hyperbaric bupivacaine-induced spinal block in adult male patients and concluded that fentanyl prolongs mean time for sensory regression upto L1 dermatome $(141 \pm 37 \mathrm{~min}, \mathrm{p}<0.05)$ and increased the duration of sensory block by $28 \%$, which is in accordance with the findings of our study. This is also in agreement with Gupta $\mathrm{K}$ et al. ${ }^{[9]}$, who compared intrathecal isobaric ropivacaine with ropivcaine -fentanyl solution and Venkata HG et al. ${ }^{[14]}$, who compared intrathecal low dose $(7 \mathrm{mg})$ bupivacaine-fentanyl mixture with $10 \mathrm{mg}$ hyperbaric bupivacaine; both found fentanyl to be effective in prolonging the mean time $(359.80 \pm 66.96 \& 200 \pm 9.1)$ to sensory block regression at $\mathrm{S} 1(\mathrm{p}<0.05)$.

In our study, addition of fentanyl in Group B produced a faster onset of motor block and the time required to reach the maximum motor block was also faster $(4.12 \pm .56 \mathrm{~min})$. It is supported by Gupta $\mathrm{K}$ et al. ${ }^{[9]}$, but it differed from the findings of Koltka $\mathrm{K}$ et al. ${ }^{[15]}$, where no significant difference was observed in the onset of motor block. The total duration of motor block (B0) was 245.02 \pm 22.95 in Group A and 196.22 \pm 16.46 in Group B $(\mathrm{p}<0.001)$ in this study. Boztuğ $\mathrm{N}$ et al. ${ }^{[16]}$ observed that duration of motor block was shorter in fentanyl group (104.20 $\pm 24.29 \mathrm{~min}$ ) which is in concurrence with the findings of our study.

Opioids and local anesthetics exert their antinociceptive effect in the spinal cord by different mechanisms. Fentanyl, a $\mu$ agonist, exerts its action by opening $\mathrm{K}^{+}$channels and reducing $\mathrm{Ca}^{++}$influx, resulting in inhibition of transmitter release. Moreover, the $\mu$ agonists also have a direct postsynaptic effect, causing hyper polarization and a reduction in neuronal activity. ${ }^{[17,18]}$ Local anesthetics like ropivacaine acts mainly by blockade of voltage-gated $\mathrm{Na}^{+}$channels in the axonal membrane. Local anesthetics may also interfere with synaptic transmission by a presynaptic inhibition of $\mathrm{Ca}^{++}$channels in addition to their effects on nerve conduction. ${ }^{[19]}$ A combination of these effects may explain the observed synergism between ropivacaine and fentanyl in our study group.

When fentanyl was added to intrathecal hyperbaric $0.75 \%$ ropivacaine, it provided better hemodynamic stability $(p<0.001)$ in our study. Maintenance of heart rate is one of the prominent features of opioids. After initial fall in MAP, Group B recovered earlier than Group A. Venkata HG et al. ${ }^{[14]}$ observed a significant decrease in blood pressure $(\mathrm{p}<0.001)$ in only bupivacaine group than in bupivacaine-fentanyl group and concluded that fentanyl provides better hemodynamic stability. This is also supported by Jagtap S et al. ${ }^{[20]}$ where better hemodynamic stability has been seen with intrathecal ropivacaine-fentanyl group.

No cases of vomiting were observed in either groups of the present study. Nausea occurred in $28 \%$ cases of Group A and $2 \%$ cases of Group B $(\mathrm{P}<0.001)$ i.e. there was decrease incidence of nausea in fentanyl group. This in agreement with Manullang TR et al. ${ }^{[21]}$ where they compared the efficacy of intrathecal fentanyl as an anti emetic and concluded that intrathecal fentnyl is superior to IV ondansetron in patients undergoing cesarean section $(\mathrm{p}=0.0002)$. This is also supported by Bogra $\mathrm{J}$ et al. ${ }^{[12]}$ where adding intrathecal fentanyl to local anaesthetic reduced intraoperative nausea.

In $2 \%$ of the cases of Group B, sedation occurred as side effect but was statistically insignificant. Pruritus, a common side effect of opioids was present in $6 \%$ of group B cases, but was statistically insignificant. However, there was no incidence of shivering in Group B compared to $24 \%$ in Group A, which was statistically significant $(\mathrm{P}<0.001)$. The reduction of shivering in group $\mathrm{B}$ can be attributed to the effect of fentanyl that was added into the subarachnoid space on the thermo regulator and could affect the afferent thermal inputs at the spinal cord. ${ }^{[22]}$ Similar findings were observed by Kararmaz A et al. ${ }^{[23]}(\mathrm{p}<0.05)$.

Although this study adds to the current knowledge on intrathecal fentanyl as an adjunct to ropivacaine, 
the following limitations should be taken into account viz. (i) different doses of ropivacaine and fentanyl, (ii) any ceiling effect of the adjuvant, (iii) any adverse effect with different doses and (iv) sedation score or pain assessment scale, etc. Hence, further study with a larger sample size is recommended to come to a definitive conclusion.

\section{Conclusion}

Intrathecal fentanyl as adjuvant to hyperbaric ropivacaine was better than intrathecal hyperbaric ropivacaine alone for lower segment caesarean section and it provided faster onset and longer duration of sensory block, early postoperative recovery from motor block, better hemodynamic stability without any significant side effects.

Acknowledgement:- Nil

Conflict of interest: Nil

\section{References}

[1]. Gupta R, Bogra J, Singh PK, Saxena S, Chandra G, Kushwaha JK. Comparative study of intrathecal hyperbaric versus isobaric ropivacaine: A randomized control trial. Saudi J Anaesth 2013;7:249-53.

[2]. Afolabi BB, Lesi FE. Regional versus general anaesthesia for caesarean section. Cochrane Database Syst Rev. 2012 Oct 17. Available from https://www.ncbi.nlm.nih.gov/pubmed/23076903. [Last accessed 2015 Aug 20].

[3]. Kuthiala G, Chaudhary G. Ropivacaine: A review of its pharmacology and clinical use. Indian J Anaesth 2011; 55:104-10.

[4]. Gupta A, Bogra J, Singh PK, Kushwaha JK, Srivastava P (2014) A Randomised Double-Blinded Dose Response Study of the Fentanyl with Hyperbaric Ropivacaine in Cesarean Section. J Anesth Clin Res 5:467. doi: 10.4172/2155-6148.1000467. Available from https://www.omicsonline.org/open-access/a-randomised-doubleblinded-dose-response-study-of-the-fentanyl2155-6148.1000467.php?aid=34018 [Last accessed 2015 Sep 20]

[5]. Fatima N, Singh NR, Singh LP, Doddaiah DB, Singh TH, Taloh Y. Comparative study of the effect of dexmedetomidine and butorphanol as epidural adjuvants in abdominal hysterectomy under intrathecal levobupivacaine anesthesia. J Med Soc 2016;30:166-71.

[6]. Kumamoto E, Mizuta K, Fujita T. Opioid actions in primary-afferent fibers-involvement in analgesia and anesthesia. Pharmaceuticals 2011;4(2): 343-65.

[7]. Singh H, Yang J, Thornton K, Giesecke AH. Intrathecal fentanyl prolongs sensory bupivacaine spinal block. Can J Anaesth 1995; 42(11):987-91.

[8]. Fischer SP, Bader AM, Sweitzer B. Perioperative evaluation. In: Miller RD, editor. Miller's Anesthesia. $7^{\text {th }}$ ed. Philadelphia: Churchill Livingstone Elsevier; 2010. p. 1002

[9]. Gupta K, Singh S, Sharma D, Gupta PK, Krishan A, Pandey M N. Intrathecal fentanyl as an adjuvant to 0.75\% isobaric ropivacaine for infraumbilical surgery under subarachnoid block: A prospective study. Saudi J Anaesth 2014;8(1):64.

[10]. McLeod G.A. Density of spinal anaesthetic solutions of bupivacaine, levobupivacaine, and ropivacaine with and without dextrose. Br J Anaesth 2004;92(4):547-51.

[11]. Fettes PD, Hocking G, Peterson MK, Luck JF, Wildsmith JA. Comparison of plain and hyperbaric solutions of ropivacaine for spinal anaesthesia. Br J Anaesth 2005;94(1):107-11.

[12]. Bogra J, Arora N, Srivastava P. Synergistic effect of intrathecal fentanyl and bupivacaine in spinal anaesthesia for cesarean section. BMC Anesthesiol 2005. Available from: http://www.biomedcentral.com/1471-2253/5/5 [Last accessed 2015 Sep 20].

[13]. Yegin A, Sanli S, Hadimioglu N, Akbas M, Karsli B. Intrathecal fentanyl added to hyperbaric ropivacaine for transurethral resection of the prostate. Acta Anaesthesiol Scand. 2005;49:401-5.

[14]. Venkata HG, Pasupuleti S, Pabba UG, Porika S, Talari G. A randomized controlled prospective study comparing a low dose bupivacaine and fentanyl mixture to a conventional dose of hyperbaric bupivacaine for cesarean section. Saudi $\mathrm{J}$ Anaesth 2015;9(2):122.

[15]. Koltka K, Uludag E, Senturk M, Yavru A, Karadeniz M, Sengul T, et al. Comparison of equipotent doses of ropivacaine-fentanyl and bupivacaine-fentanyl in spinal anaesthesia for lower abdominal surgery. Anaesth Intensive Care 2009;37(6):923-8.

[16]. Boztuğ N, Bigat Z, Ertok E, Erman M. Intrathecal ropivacaine versus ropivacaine plus fentanyl for out-patient arthroscopic knee surgery. Journal of international medical research. 2005 Jul 1;33(4):365-71.

[17]. Fan Y, Ji M, Zang L, Wang W, Yin Q, Xu J, et al. Comparison of epidural tramadol-ropivacaine and fentanyl-ropivacaine for labor analgesia: a prospective randomized study. Ups J Med Sci 2011;116(4):252-7.

[18]. Ocana M, Del Pozo E, Barrios M, Robles LI, Baeyens JM. An ATP-dependent potassium channel blocker antagonizes morphine analgesia. Eur J Pharmacol 1990;186(2):377-8.

[19]. Dickenson AH. Mechanisms of the analgesic actions of opiates and opioids. Br Meal Bull 1991;47(3):690-702.

[20]. Jagtap S, Chhabra A, Dawoodi S, Jain A. Comparison of intrathecal ropivacaine-fentanyl and bupivacaine-fentanyl for major lower limb orthopaedic surgery: A randomised double-blind study. Indian J Anaesth 2014;58(4):442.

[21]. Manullang TR, Viscomi CM, Pace NL. Intrathecal fentanyl is superior to intravenous ondansetron for the prevention of perioperative nausea during cesarean delivery with spinal anesthesia. Anesth Analg 2000;90(5):1162-6.

[22]. Techanivate A, Rodanant O, Tachawattanwisel W, Somsiri T. Intratechal fentanyl for prevention of shivering in cesarean section. J Med Assoc Thai. 2005;88(9):1214-21.

[23]. Kararmaz A, Kaya S, Turhanoglu S, Ozyilmaz MA. Low-dose bupivacaine-fentanyl spinal anaesthesia for transurethral prostatectomy. Anaesthesia 2003;58(6):526-30. 